\title{
Assessment of Static and Dynamic Stresses Horse-Shoe Tunnel With Connecting GalleRY using Finite Element Method: (As a Case Study)
}

\author{
Jaafar MOHAMMED ${ }^{1}$, Eva HRUBESOVA ${ }^{2}$
}

\author{
${ }^{1}$ Department of Geotechnics and Underground Engineering, Faculty of Civil Engineering, \\ VSB - Technical University of Ostrava, Ludvíka Podeste 1875/17, Ostrava - Poruba, Czech Republic \\ ${ }^{2}$ Department of Geotechnics and Underground Engineering, Faculty of Civil Engineering, \\ VSB - Technical University of Ostrava, Ludvíka Podeste 1875/17, Ostrava - Poruba, Czech Republic
}

jaafar.brifkani@uod.ac, eva.hrubesova@vsb.cz

DOI: $10.31490 /$ tces-2018-0004

\begin{abstract}
This paper illustrates the use of MIDAS GTS NX to investigate the tunnel's simulation in order to highlight the effect of static and dynamic load on the behaviour of tunnel to compare this response expressed in terms of displacement and stresses acting on the tunnel and ground. Main tunnel is located in the ground having uniform property throughout its extent, connecting gallery is located perpendicular to the main tunnel, the shotcrete and rock bolts for each tunnel will be installed.
\end{abstract}

\section{Keywords}

Tunnel, Numerical model, Static load, Dynamic load, Earthquake, Displacement.

\section{Introduction}

According to recent studies and observed failures of underground structures many researchers had been addressed the design and construction of tunnel lining against static/dynamic loads and earthquake vibration to get the best design use different methods include empirical methods, analytical methods and numerical methods. The 3D numerical models using finite element method software MIDAS GTS NX investigation will be carried out in order to highlight the effect of the tunnel lining response under static and dynamic.

The 3D numerical analysis prepared to simulate the static and dynamic behavior of a tunnel and connecting gallery, were undertaken to investigate the tunnel seismic response and to compare this response expressed in terms of displacement and stresses acting on the tunnel and rock mass.

The materials and properties of tunnels and rock mass were taken from the MIDAS GTS tutorials without the experimental testing like tensile strength as a case study, the Design Response Spectrum of UBC (1997) is mentioned in this manual also.Due to the application of the static load the stress-strain state around the tunnel periphery is changed, otherwise the result show that the applied dynamic stress is not negligible for underground structure, but it is less dangerous in comparison with the others.

The main application of the numerical methods in the field of the tunnel engineering is to analysis of the stress, strain and deformations 4. Response spectrum analysis expresses the natural period, natural angular frequency or natural frequency at the maximum physical quantity response as a function when a dynamic load is applied to the structure [1]. Shallow tunnels through fractured zones exposed to increased pressure, resulting in damage to the lining and deformation. Tunnels crossing fault zones are exposed to increased stresses during earthquake loading, leading to complicated cracking and large differential displacements [12].

The dynamic responses of a buried tunnel in general, and its seismic responses, in particular, are of much interest [2].Although underground structures such as tunnels are more resistant to earthquakes than surface structures 5. Finite element methods allow the computation of ground displacement at every point within the ground. The geometry, initial conditions, excavation stages and ground behavior can be properly modeled using the numerical approach 3 . 
Stress and displacement balance of forces around the tunnel are adversely affected and due to redistribution of these forces that create undue concentration in some areas, instability occurs in the tunnel. Their research also concludes that increasing the stiffness of the support system can increase the effect of the seismic loads 8 .

The pressure on the lining of an underground space or a tunnel increases with time. This is due to the time-dependent mechanical behavior of the surrounding rocks or soil [6].The maximum change of internal forces during an earthquake occurs in shear force, then bending moment. Moreover, the normal force of tunnel lining is less affected by seismic actions 13 .

It is very likely that not only the shotcrete is affected by deterioration. Also the contact between the ground and the shotcrete shell and the contact between the shotcrete shell and the inner liner can be affected. Further, the properties of the ground around the opening may change due to weathering [7]. While the general public is often skeptical about the performance of underground structures, tunnel designers know that underground structures are among the safest shelters during earthquakes, based primarily on damage data reported in the past [9], [10] and [11.

\section{Conditions of Surrounding Ground}

Adam McIntyre [?] clears up in short the condition of surrounding ground due to seismic condition listed as:

- Seismic waves propagate faster in hard/dense materials.

- Less energy will be released at places where the ground is harder than the tunnel structure,

- tunnels in harder ground will tend to deform with the ground and suffer less damage,

- conversely, tunnel structures in weaker soil/rock will absorb larger amounts of seismic energy and suffer greater damage.

- Disturbance to the plastic zone between the tunnel wall and reinforcement/lining structure could cause excessive vibration due to passing seismic waves.

- Disturbance caused by cave-in/collapse during tunneling, squeezing ground, inclined stresses, etc.
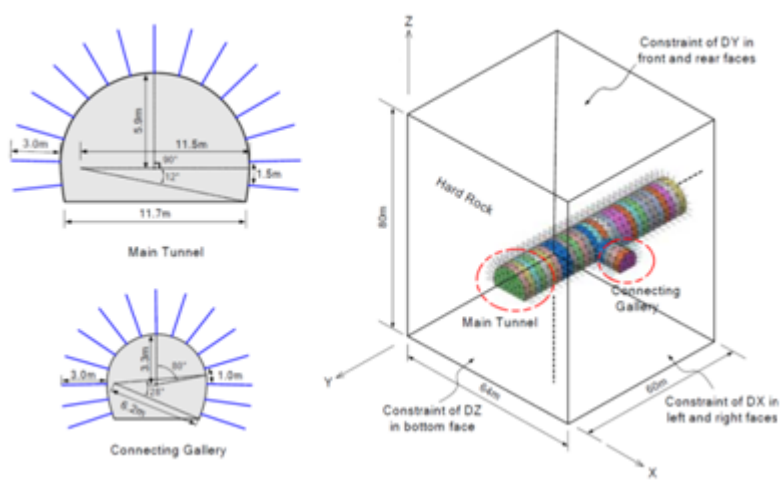

Fig. 1: Tunnel profile showing the geometry of the model [1]

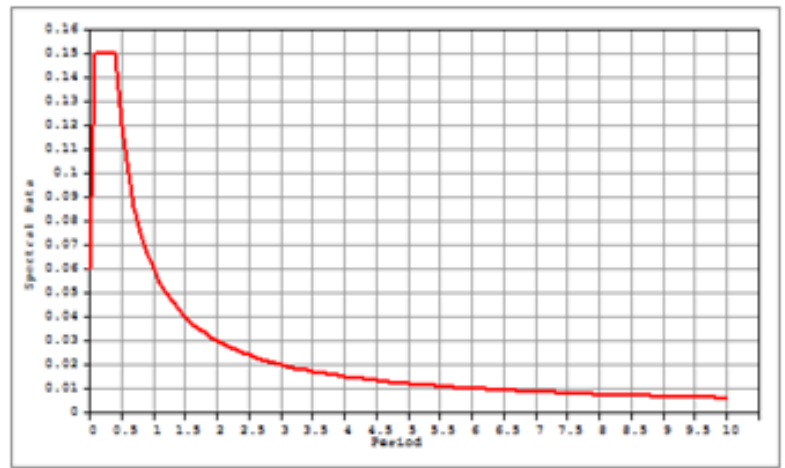

Fig. 2: Modified Response Spectrum using UBC (1997); Damping Ration $=0.05$; Seismic Coefficient: $C_{a}=0.06 C_{v}=$ 0.06; Normalized Acceleration [1]

\section{Difination of Ground and Structural Materials}

This paper studies the 3D model with gravity direction in Z direction. Design response spectrum of UBC (1997) is used as seismic response spectrum. The dimension of the model are $(x=64, y=60, z=80) \mathrm{m}$. After tunnel model is performed in the MIDAS GTS NX (geometry, input data, mesh, etc.) the model is run to analyze the tunnel stability and deformation under static and dynamic conditions by calculated the value of each mesh node based on 3D finite element method to simulate the effect of earthquake on tunnel and ground. Tab. 1 and Tab. 2 shows the ground materials, shotcrete and rock bolt, the material property of shotcrete and rock bolt and the section property of shotcrete and rock bolt respectively. 


\begin{tabular}{|c|c|}
\hline Name & Hard Rock \\
\hline Material model & Mohr- Coulomb \\
\hline Modulus of Elasticity $(E)[\mathrm{kPa}]$ & $5,000,000$ \\
\hline Poisson's Ratio $(\nu)[-]$ & 0.2 \\
\hline Unit Weight $(\gamma)\left[\mathrm{kN} / \mathrm{m}^{3}\right]$ & 25 \\
\hline Unit Weight Saturated $(\gamma)\left[\mathrm{kN} / \mathrm{m}^{3}\right]$ & 25 \\
\hline Cohesion $(c)[\mathrm{kPa}]$ & 300 \\
\hline Friction Angle $(\varphi)\left[{ }^{\circ}\right]$ & 40 \\
\hline Tensile Strength $[\mathrm{kPa}]$ & 2,942 \\
\hline Coefficient of Lateral Pressure $\left(K_{o}\right)[-]$ & 0.25 \\
\hline
\end{tabular}

Tab. 1: Rock MassMaterials

\begin{tabular}{|c|c|c|}
\hline Name & Shotcrete & Rock Bolt \\
\hline Geometrical type & Plane & Line \\
\hline Element Type & Shell (2D element) & Line (1D element) \\
\hline Modulus of Elasticity $(E)[\mathrm{kPa}]$ & $15,000,000$ & $200,000,000$ \\
\hline Poisson's Ratio $(\nu)[-]$ & 0.2 & 0.3 \\
\hline Weight Density $(\gamma)\left[\mathrm{kN} / \mathrm{m}^{3}\right]$ & 24 & 77 \\
\hline Thickness $[\mathrm{m}]$ & 0.16 & - \\
\hline Radius $[\mathrm{m}]$ & - & 0.025 \\
\hline
\end{tabular}

Tab. 2: The material property of shotcrete and rock bolt of both main tunnel and connecting gallery

\section{Simulation and Calibration of the Numerical Model}

The tunnel model consists of two parts: one is the main tunnel running through the ground along $\mathrm{Y}$ - Axis and the other part is the gallery which has a short extension along X - Axis and its located perpendicular to the main tunnel. The depth of main tunnel under ground surface is $(z=36.8 \mathrm{~m})$ and located in the ground having uniform property throughout its extent. In each tunnel, shotcrete and rock bolts will be installed. Construction stage will be defined at each stage of excavation and the process of construction stage of connecting gallery start after the end of main tunnel construction stages. The type of lining for both the main tunnel and gallery are shotcrete. The rock bolts method used to support tunnels which are connected to the ground. The rock bolts and shotcrete of the main tunnel will be installed right after the excavation. The subsoil has been meshed with tetrahedral solid elements and the tunnel mesh consists of curved shell elements of uniform thickness $0.16 \mathrm{~m}$. The rock bolts composed of 1D reinforced bar elements of uniform cross - section area $(0.001963) \mathrm{m}^{2}$. The Eigenvalue analysis reveals 7 th and 15 th to be the most influential modes for the vertical vibration of the tunnel - rock mass system. Subsequently, a response spectrum analysis has been performed with an input of a design response spectrum applied in horizontal $\mathrm{X}$ direction as shown in Fig. 2. The subsoil is assumed to have a damping ratio of 0.05 . Gravity is calculated automatically by multiplying the inputted unit weight of the ground, the structure ge-

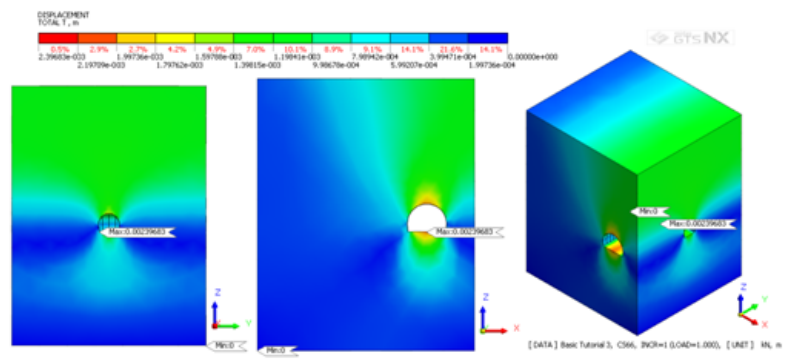

Fig. 3: Static: Distribution of total displacement (including max. and min. value)in $2 \mathrm{D}$ and $3 \mathrm{D}$ of rock mass

ometry and the acceleration of gravity it can be easily set by inputting a scale factor of direction. The total length of the main tunnel along y direction is 60 meters. The excavation of the tunnel is executed in full face excavation. The construction stages have 66 stages. The considered section length of tunnel excavated in a single cycle is assumed as $2 \mathrm{~m}$. In 3D model analysis, displacement constraints are applied in $\mathrm{x} \mathrm{di-}$ rection for left/right, y direction for front/back, xyz direction for the bottom part as shown in Figs. 3 7. The initial stage of model corresponds to the self - weight only and the ground boundary conditions are activated. GTS NX automatically recognizes and sets the boundary conditions for the model. The maximum and minimum value of Max.principal stresses and Min. principal stresses $\left(\sigma_{1}\right.$ and $\left.\sigma_{2}\right)$ respectively are shown in Figs. 8- 11, for both static and dynamic result analysis and are increased at dynamic analysis than static. 


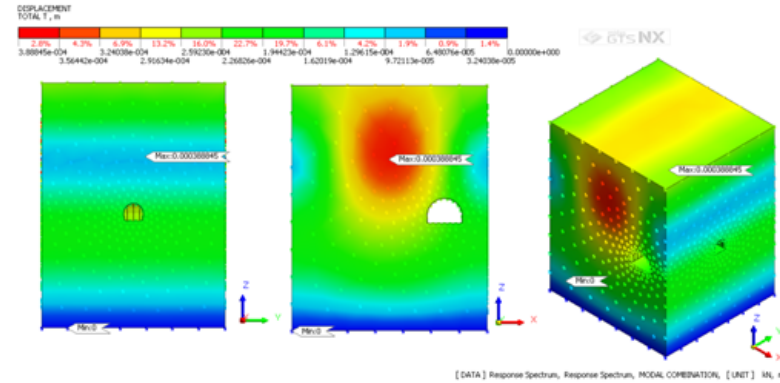

Fig. 4: Dynamic: The Max. and Min. value of total displacement in $2 \mathrm{D}$ and $3 \mathrm{D}$ of rock mass

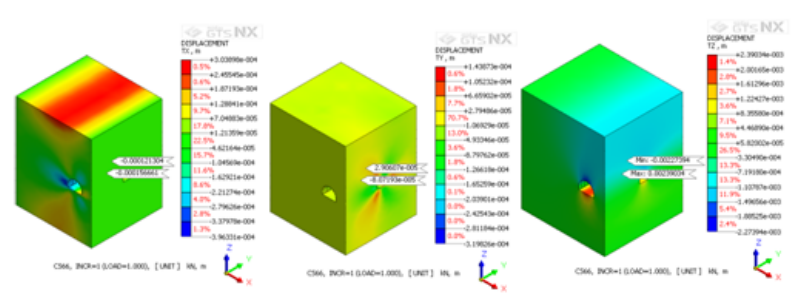

Fig. 5: Static analysis: Displacement distribution of rock mass in direction $\mathrm{X}, \mathrm{Y}$ and $\mathrm{Z}$

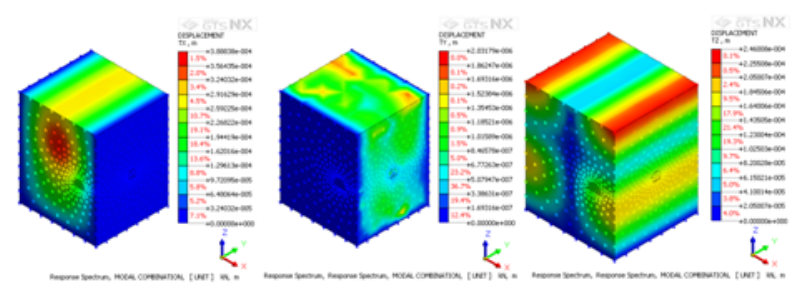

Fig. 6: Static analysis: Displacement distribution of rock mass in direction $\mathrm{X}, \mathrm{Y}$ and $\mathrm{Z}$
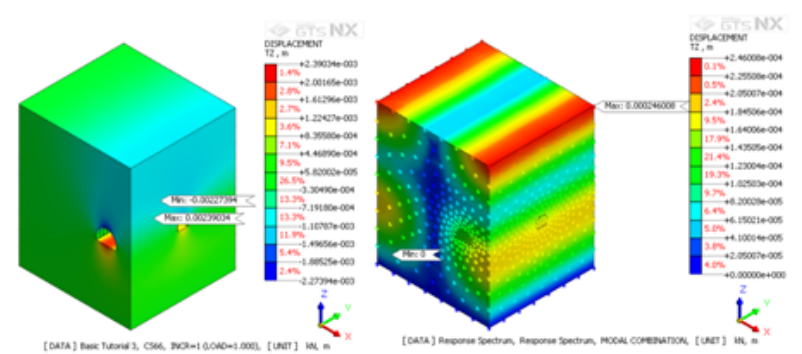

Fig. 7: The total displacement in static and dynamic analysis at TZ Translation(V)

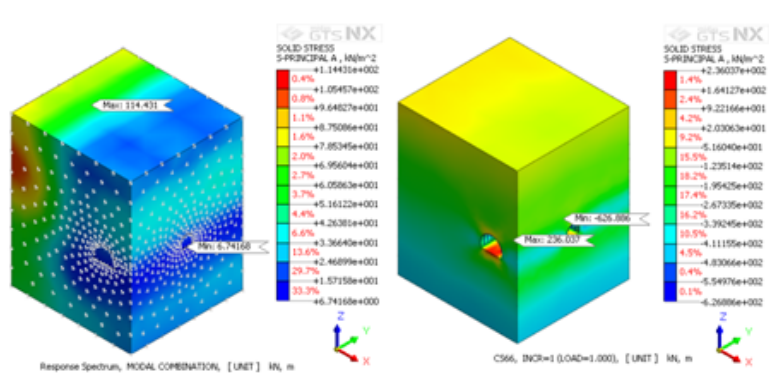

Fig. 8: The Max. and Min. values of maximum principal stresses of dynamic and static

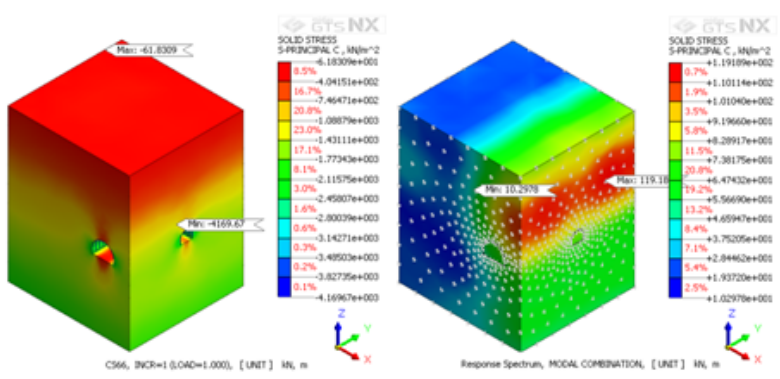

Fig. 9: The Max. and Min. values of minimum principal stresses of static and dynamic analysis
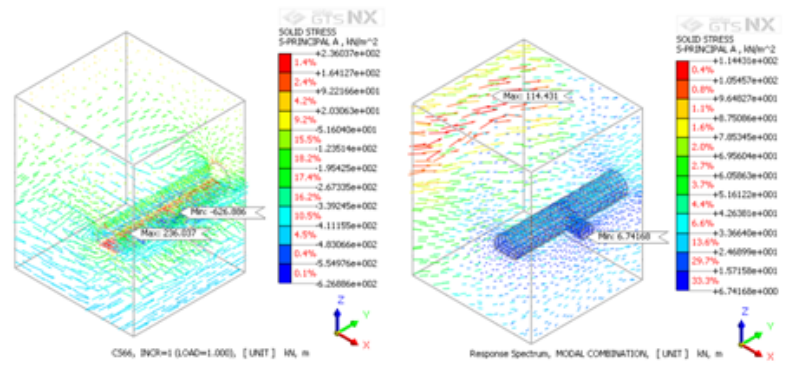

Fig. 10: The Max. and Min. value of maximum principal stresses (vector) distribution of static and dynamic analysis

\section{Conclusion}

After tunnel model is created in MIDAS GTS NX, the model is run to analyze the tunnel stability and deformation in static and dynamic conditions by calculated the value of each mesh node based on 3D finite element method to simulate the effect of earthquake on tunnel and ground. From the results of model analysis, it can be noticed that three dimensional analyses which simulates the progress of works, as mentioned in Tab. 3 and Tab. 4 , and Figs. 3 - 5 , above shows the result of the maximum and minimum values. In this study, the following conclusions are drawn: Figs. 3 - 7. shows the displacement in static and dynamic conditions. The maximum and minimum principle stresses as shown in Figs. 8 - 11 for both static and dynamic analysis. Fig. 12, in static analysis show the stresses
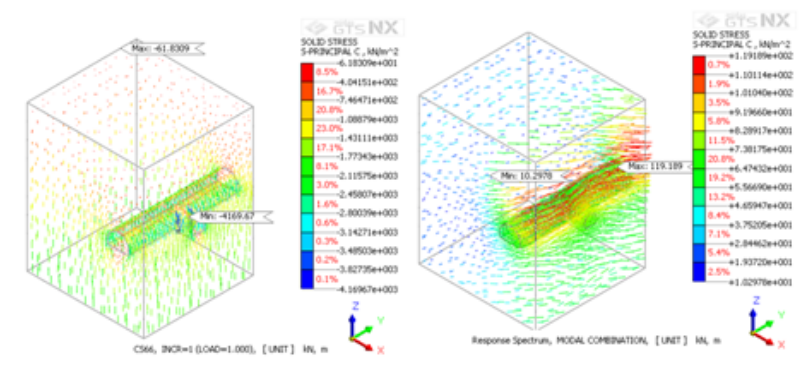

Fig. 11: The Max. and Min. value of minimum principal stresses (vector) distribution of static and dynamic analysis 


\begin{tabular}{|c|c|c|c|}
\hline \multirow{4}{*}{ Static } & Displacement $[\mathrm{m}]$ & Max. Principle stresses $[\mathrm{kPa}]$ & Min. Principle stresses $[\mathrm{kPa}]$ \\
\cline { 2 - 4 } & Max. value & Max. value & Max. value \\
\cline { 2 - 4 } & 0.002397 & 236.037 & -61.8309 \\
\cline { 2 - 4 } & Min. value & Min. value & Min. value \\
\cline { 2 - 4 } & 0.0 & -626.886 & -4169.67 \\
\hline
\end{tabular}

Tab. 3: The result in maximum and minimum values in static analysis

\begin{tabular}{|c|c|c|c|}
\hline \multirow{4}{*}{ Dynamic } & Displacement $[\mathrm{m}]$ & Max. Principle stresses $[\mathrm{kPa}]$ & Min. Principle stresses $[\mathrm{kPa}]$ \\
\cline { 2 - 4 } & Max. value & Max. value & Max. value \\
\cline { 2 - 4 } & 0.000389 & 114.431 & 119.189 \\
\cline { 2 - 4 } & Min. value & Min. value & Min. value \\
\cline { 2 - 4 } & 0.0 & 6.74168 & 10.2978 \\
\hline
\end{tabular}

Tab. 4: The result in maximum and minimum values in dynamic analysis

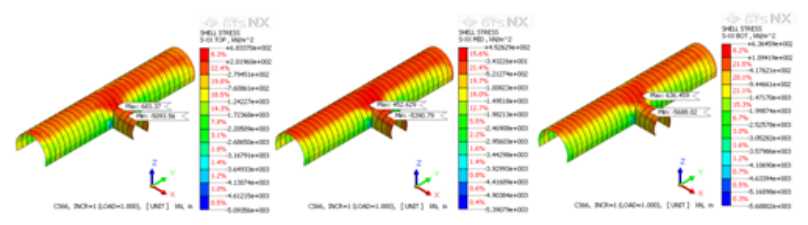

Fig. 12: Static analysis: Stresses distribution on shotcrete

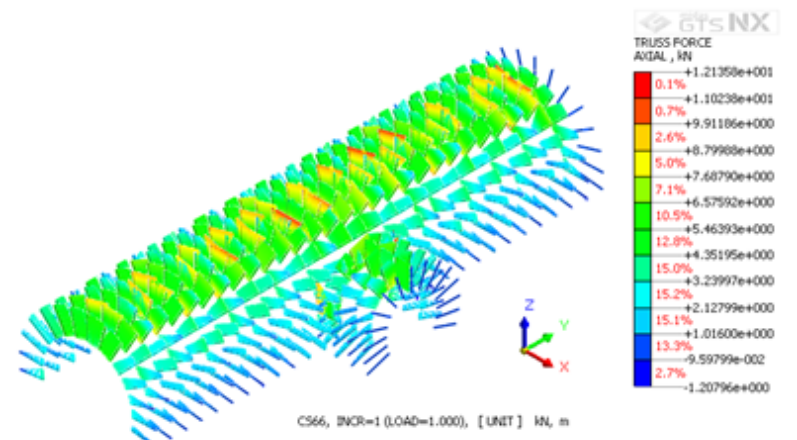

Fig. 13: Static: Axial forces distribution in the Rock Bolts

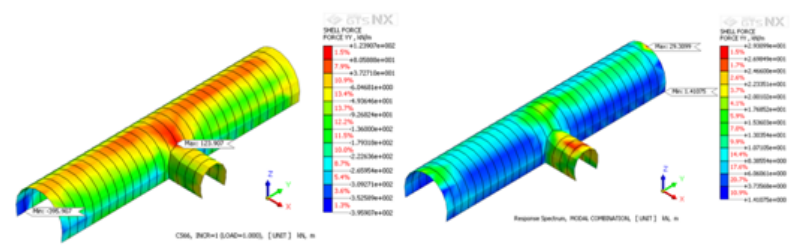

Fig. 14: Static and dynamic: Axial forces distribution in the shotcrete distribution on shotcrete and the axial force distribution on shotcrete are shown in Fig. 14. for static analysis. Fig. 13, in static analysis shows the axial forces distribution in the Rock Bolts. Due to the application of the static load the stress - strain state ground the tunnel periphery is changed, the primary stress state is disrupted and the potential of instability increases, otherwise the result show that the applied dynamic stress is not negligible for underground structure.

\section{Acknowledgment}

The paper was prepared with the support of the Competence Centers of the Technology Agency of the Czech Republic (TACR) within the project Center for Effective and sustainable transport infrastructure (CESTI), project number TE01020168.

\section{References}

[1] MIDAS. GTS NX On-line Manual [cit. 02.01.2017] [EN] http://manual.midasuser.com/en_ common/GTS

[2] XIAOQING, W., XIANLONG, J., PUYONG, W. and Y. ZHIHAO. Parallel Dynamic Analysis of a Large - Scale Water Conveyance Tunnel under Seismic Excitation Using ALE FiniteElement Method. Received: 15 December 2015; Accepted: 22 January 2016; Published: 28 January 2016. DOI: www .mdpi . com/journal/ applsci 10.3390/app6020036.

[3] RAluCA, A., MOldovan, A. and A. POPA. The influence of different tunnel cross sections on surface settlement. Acta Technica Napocensis: Civil Engineering \& Architecture. 2013, vol. 56. http://constructii.utcluj.ro/ ActaCivileng 
[4] RANA M., SAJID, I. and S. KHAN/KABINDRA MAN. Stability Analysis of Shallow Tunnel of NorraLänken. OMaster of Science Thesis. Royal Institute of Technology (KTH), 2011, ISNN 1652-599X.

[5] TSERING T. The Impact of Earthquakes on Tunnels in different Rock Mass Quality Q: A numerical analysis Master Thesis in Geosciences. University of Oslo,2001. http://www.duo.uio.no

[6] KHOSHBORESH RAHIM A. A Study on Deformation of Tunnels Excavated in Fractured Rocks. Master of Science (MSc). Quebec, Canada, 2013.

[7] MÖDLHAMMER H. Numerical Methods for Tunneling using ABAQUS and Investigation of LongTime-Effects of the Shotcrete Shell and its Impact on the Combined Support System. Master Thesis. Montan universit ät Leoben/Österreich, 2010.

[8] HOSSEINI, N., ORAEE, K. and M. GHOLINEJAD. Seismic analysis of horseshoe tunnels under dynamic loads due to earthquakes, in Aziz, N (ed). In: 10th Underground Coal Operators' Conference. University of Wollongong \& the Australasian Institute of Mining and Metallurgy, 2010, 140-145

[9] HOEK, E., CARRANZA - TORRES, C. and B. CORCUM. Hoek-Brown failure criterion 2002 Edition. In: NARMS-TAC Conference. Toronto, 2002, 1, 267-273. Available at: WwW. rocscience.com

[10] YOUSSEF, M., HASHASH, A., HOOK JEFFREY, J., SCHMIDT, B. and J. I-CHIANG YAO. Seismic design and analysis of underground structures. Tunnelling and Underground Space Technology. 16, 247-293, 2001, PII: S $0886-77$ $98 \mathrm{Z} 01.000051$ - 7 .

[11] AKHLAGHI, T. and A. NIKKAR. Effect of Vertically Propagating Shear Waves on Seismic Behavior of Circular Tunnels. Hindawi Publishing Corporation. Scientific World Journal. 2014, Article ID 806092, 10 pages. Received 8 August 2013; Accepted 19 October 2013; Published 30 January 2014. DOI: http://dx.doi.org/10 . 1155/2014/806092.

[12] McINTYRE A. Effects of earthquakes on tunnels. EOSC 547: Tunneling and Underground Design

[13] HAMDY, H.A., ABD-EL, R., ENIEB, M., KHALIL, A.A. and S.H.A.ABDOU. Seismic Analysis of Urban Tunnel Systems for the Greater Cairo Metro Line. 2015, No.4. EJGE Vol. 20, Bund. 10. 